\title{
Knowledge about Anemia among Pregnant Women in Tertiary Hospital
}

\author{
Fahmida Sultana ${ }^{1}$, Gulshan Ara ${ }^{2}$, Tania Akbar ${ }^{3}$, Rayhana Sultana $^{4}$
}

\begin{abstract}
Introduction: To evaluate knowledge about anemia among pregnant women visiting in OPD for antenatal care. Materials and Methods: A cross sectional study was conducted in tertiary hospital Dhaka, from outdoor patient department of gynecology and obstetrics, to assess the knowledge about anemia among pregnant women and also to find out the percentage and type of anemia. A total 396 pregnant women were interviewed and information were collected by pre designed data collection sheet using various parameters. Interviews conducted by direct questionnaire, blood samples were collected at same setting. Results: The mean age was 25.92 \pm 5.05 , highest number $39.65 \%$ were age group $21-25$ years, $28.79 \%$ were age group -30 years, $15.91 \%$ were age group $31-35$ years, $11.36 \%$ were found age group $<20$ years. Regarding antenatal visit during pregnancy, 25.8\% pregnant women visited in 1 st trimester, $46.7 \%$ pregnant women visited in second trimester, and $27.5 \%$ in 3rd trimester. Also $11.11 \%$ patients had anemia in first trimester, $39.39 \%$ anemic in 2nd trimester, $14.39 \%$ pregnant women anemic in third trimester and $35.10 \%$ had normal findings. And $67 \%$ pregnant woman's had knowledge about ANC 32\% had no knowledge. Conclusion: In this cross sectional study it was found that poor knowledge about anemia and less iron intake is the main cause for anemia during pregnancy.
\end{abstract}

Keywords: Anemia, Iron deficiency, Serum ferritin level.

Number of Tables: 03; Number of Figures: 03; Number of References: 21; Number of Correspondences: 04

*1. Corresponding Author:

Dr. Fahmida Sultana

Assistant Professor

Department of Obs and gynae

Enam Medical College and Hospital,

Savar, Bangladesh.

Email: fahmidasultana00@gmail.com

2. Dr. Gulshan Ara

Professor \& Head of the Department,

Enam Medical College and Hospital,

Savar, Bangladesh

3. Dr. Tania Akbar

Assistant Professor

Enam Medical College, Savar, Bangladesh

4. Dr. Rayhana Sultana

Associate Professor

Department of Physiology

Enam Medical College and Hospital,

Savar, Bangladesh

\section{Introduction}

In pregnancy anemia in pregnancy is the major public health issue in worldwide now a day. WHO assessments that more than half of pregnant women in the world have hemoglobin level indicative of anemia $(<11.0 \mathrm{gm} / \mathrm{dl})$. The prevalence of anemia may however as high as $56 \%$ or $61 \%$ in developing countries. Cases of anemia still high in pregnant women have low consciousness about the importance of anemia prevention and the danger of less iron supplement ${ }^{1}$.
Pregnant women are mostly suffering from deficiency anemia in our country Bangladesh. This is the demand for iron and other vitamins increased due to physiological burden of pregnancy. Folate deficiency is a minor component contributing to anemia ${ }^{2}$. Folate deficiency may be marked by co-existing iron deficiency. Vitamin B12 deficiency \& thalassemia major are usually associated with infertility. Detoriorus effects occur in mother as well as baby as a result of anemia, which is multifactorial as a community like ours. Multiparity, poor socio-economical, educational status \& lack knowledge are the principal reasons for a high prevalence of anemia in our population ${ }^{3}$.

Microcytic hypochromic anemia resulting from iron deficiency is the most frequent from anemia (76\%), followed by folate deficiency (20\%) and combined folate and iron deficiency $20 \%{ }^{4}$.

Globallyanemia is a major cause of morbidity and mortality, mainly in the developing countries, correction of these continues is an insurmountable challenge ${ }^{5}$. Iron folate supplement of pregnant women prevent a deterioration of the anemic condition during the increased physiological burden of pregnancy ${ }^{6}$.

Current knowledge indicates that iron deficiency anemia in pregnancy is a risk factor for preterm delivery and subsequent low birth weight, and possibly for inferior neonatal death. For women who enter pregnancy with reasonable iron stories. Iron supplements improve iron status during pregnancy and for a considerable length of time post preterm, thus providing some protection against iron deficiency in the subsequent pregnancy. Mounting evidence indicates that maternal iron deficiency in pregnancy reduce fetal iron stores, perhaps well in the first year of life ${ }^{7}$. As most pregnant women sufficing from deficiency anemia, dietetic advice should be given with due consideration to socio-economic condition, food habits \& tests of individual consideration to the socio-economic condition, food habits $\&$ test of individual. Supplementary iron therapy is needed for all pregnant mothers form 16 weeks on wards. Above $10 \mathrm{gm}$ of $\mathrm{Hb}, 1$ tab of ferrous sulfate containing $60 \mathrm{mg}$ of elemental iron is enough ${ }^{8,9}$. 
Oral iron is gold standard of treatment of mild to moderate iron deficiency anemia.

Total body iron content in normal adult caries from 3-5gm Hemoglobin iron constitutes approximately $60-70 \%$ of total body iron. Storage iron occurs in two forms a) ferritin and b) hemosiderin. Patient with Hb level 9 gm or less should be subjected to full hematological investigation ${ }^{10}$.

To ascertain the type of anemia in pregnant mother peripheral blood flim estimation is also helpful. Abundant presence of small pale staining cells with variation in size (anisocytosis) and shape (poikilocytosis) suggest microcytic hypo chromicanemia, reticulocyte may be slightly raised. There is also evidence indicating that preeclampsia \& eclampsia occurs more frequently in patients with iron deficiency. In a report of over 54,000 pregnancy in the Cardiff area of south wales, the incidence of low birth weight, prematurity \& perinatal mortality was found to increase when maternal hemoglobin concentration was in anemic range $<104 \mathrm{~g} / 1$ before 24 weeks of gestation. There are marked physiological changes in the composition of the blood in healthy pregnancy, mainly to combat the risk of hemorrhage at delivery. Plasma volume and red blood cell mass increased by $50 \%$ and $18-25 \%$ respectively, resulting in dilutional decrease in $\mathrm{Hb}$ concentration called the physiological anemia of pregnancy, maximum at 32 weeks of gestation. Pathological anemia of pregnancy, maximum at 32 weeks of gestation. Pathological anemia is due to iron deficiency ${ }^{11}$.

In Bangladesh, two different surveys have estimated the anemia prevalence among pregnant women to be $50 \%$ \& $59 \%$. I these surveys blood samples are analyzed only to measure hemoglobin concentration. It is estimated that in 1980, the global prevalence of anemia was over 30\%. 1.3 billion out of the global population of 4.4 billion. Of this 1.2 billion lived in developing countries. About half of the pregnant women of the world are anemic. Prevalence of anemia ( $\mathrm{Hb} \quad 10 \mathrm{gm} / \mathrm{dl}$ ) is highest among pregnant women in developing countries. In South East Asian countries 75\% pregnant women are anemic. In Bangladesh percentage is $53 \%$.

Our country is a developing country, women become pregnant with preexisting anemia because of lack of knowledge, low socio-economic condition, and they are not aware about anemia \& not frequently take prenatal care. So an anemic woman is therefore at increase jeopardy ${ }^{12}$. So, our main goal was to wasto evaluate the knowledge of pregnant women about anemia in tertiary hospital.

\section{Objective}

\section{General objective:}

- To evaluate the knowledge about anemia among pregnant women for antenatal care.

\section{Specific objective:}

- To assess percentage of anemia in pregnant women in different trimester.

- To determine types of anemia
- To identify treatment about anemia among pregnant women.

\section{Materials and Methods}

This was a cross sectional study. This study was conducted at the outdoor department of obstetrics and gynecology of tertiary hospital, Dhaka from February 2010 to August 2010. Sample size was determined by using the following formula:

$\mathrm{n}=\mathrm{z}^{2} \mathrm{pq} / \mathbf{d}^{2}$

where $\mathrm{n}=384.16$

total case $=385$

here $\mathrm{n}=$ the desired sample size

$\mathrm{z}=$ the standard normal deviate, usually set at 1.96 corresponds to the $95 \%$ continence level.

$\mathrm{P}=$ the proportion in the target population estimated to have a particular characteristics and desire accuracy at $50 \%$.

$\mathrm{D}=$ degree of accuracy desired, usually set at 0.05 .

Inclusion criteria are normal pregnant women in all trimester andpregnant mother without pregnancy complication.

Exclusion criteria are patients with APH or other obstetrical emergency, patients with eclampsiaand patients with medical disorder.

\section{Method of collection of blood samples:}

Maintaining all ascetic precaution $6 \mathrm{ml}$ of venous blood was drawn from the antecubital vein of each pregnant women in the sitting position. $2 \mathrm{ml}$ of the blood was taken in EDTA tube for $\mathrm{HB} \%$ and peripheral blood film $4 \mathrm{ml}$ of blood was immediately transferred into clear dry test tube and was centrifuged within one hour of collection. The serum thus obtained was stirred at $70^{\circ} \mathrm{C}$ until assayed.

\section{Data collection and analysis:}

Data will be collection in predesigned data collection sheet using various parameters. Interviews conducted using direct questionnaire and all information will be noted in pre from data collection sheet. Data were compiled and appropriate statistical package for social science (SPSS). P value $<0.05$ was taken as minimum level of significance.

\section{Results}

In table- 1 shows age distribution of the pregnant women where maximum (39.65\%) pregnant women belongs to 26-30 age group,whereas only $11.36 \%$ pregnant women belongs to $\leq 20$ age group. The following figure is given below in detail:

Table-I: Age distribution of the pregnant women.

\begin{tabular}{lccc}
\hline Age in years & Number & $\%$ & Mean \pm SD \\
\hline$\leq 20$ & 45 & $11.36 \%$ & \\
$21-25$ & 157 & $39.65 \%$ & \\
$26-30$ & 114 & $28.79 \%$ & $25.92 \pm 5.05$ \\
$31-35$ & 63 & $15.91 \%$ & \\
36 and above & 17 & $4.29 \%$ & \\
\hline
\end{tabular}


Data was expressed as Mean \pm SD

$\mathrm{SD}=$ standard deviation

$\%=$ percent

In figure-1 shows knowledge about antenatal care among pregnant women where $67.42 \%$ pregnant women had knowledge about ANS. The following figure is given below in detail:

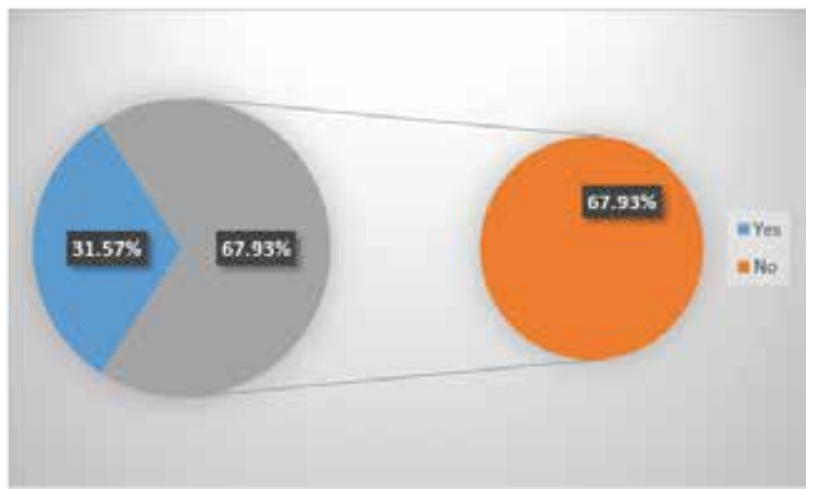

Figure-1: Knowledge about anemia during pregnancy in pregnantwomen.

In figure-2 shows knowledge about of pregnant women about correction of anemia by taking iron tablet during pregnancy where 396 women were intermixed among them only $26.8 \%$ knew daily iron tab intake during pregnancy helps to correct anemia. but maximum $73.2 \%$ had no knowledge. The following figure is given below in detail:

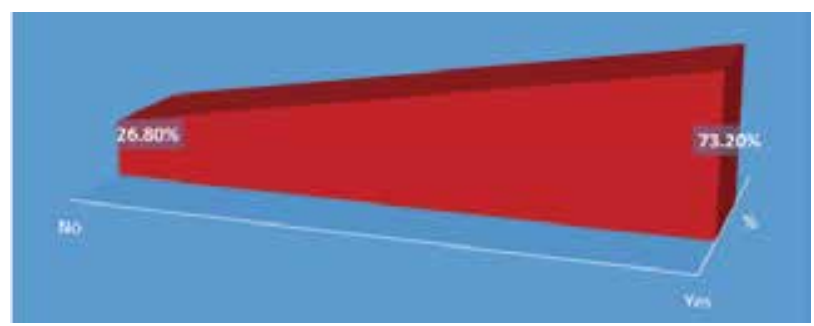

Figure-2: Knowledge about of pregnant women

about correction of anemia by taking iron tablet during pregnancy

In table-II shows knowledge about correction of anemia taking anti helminthic where total 396 women only $4.8 \%$ knows that anti helminthic drug helps to correct anemia. The following table is given below in detail:

Table-II: Knowledge about correction of anemia taking anti helminthic.

\begin{tabular}{|c|c|c|}
\hline $\begin{array}{l}\text { Correction of anemia } \\
\text { taking anti helminthic }\end{array}$ & Number & $\%$ \\
\hline Yes & 19 & $4.8 \%$ \\
\hline No & 377 & $95.20 \%$ \\
\hline
\end{tabular}

In figure-3 shows knowledge of pregnant women about effect of anemia on fetus where only $20 \%$ of pregnant women had knowledge about the effect of anemia. The following figure is given below in detail:

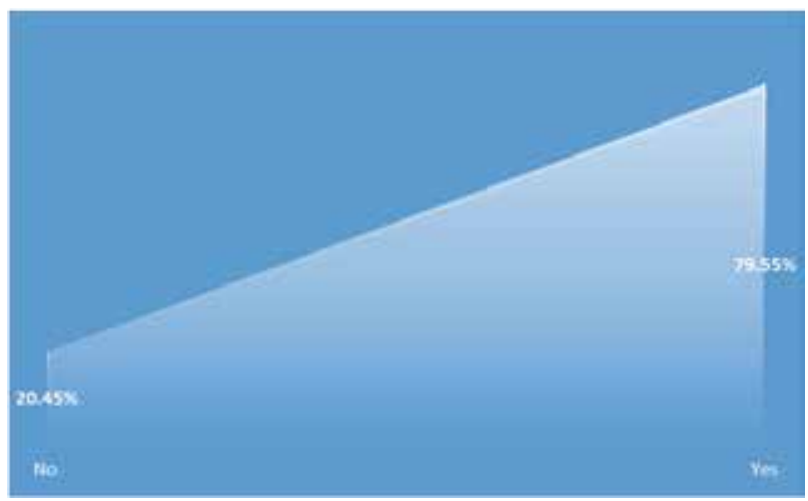

Figure-3: Knowledge of pregnant women about effect of anemia on fetus.

In table-III shows hemoglobin level of pregnant women where $41.16 \%$ were mildly anemic, $22.22 \%$ were moderately anemic. The following table is given below in detail:

Table-III: Hemoglobin level of pregnant women.

\begin{tabular}{llll}
\hline $\begin{array}{l}\text { Hemoglobin } \\
\text { level of } \\
\text { pregnant }\end{array}$ & Number & $\%$ & Mean \pm SD \\
women & & & \\
\hline Severe & 6 & $1.52 \%$ & \\
Moderate & 88 & $22.22 \%$ & \\
Mild & 163 & $41.16 \%$ & $10.51 \pm 1.20$ \\
No anemia & 139 & $35.10 \%$ & \\
\hline \multicolumn{4}{c}{ Data was expressed as Mean \pm SD } \\
\multicolumn{4}{c}{ SD $=$ standard deviation } \\
$\%=$ percent
\end{tabular}

\section{Discussion}

A total 396 students are the interviewed for this study, for the highest number (46.7\%) visited in 2nd trimester, $27.5 \%$ were in third and $25.8 \%$ in third trimester. A survey of pregnant women in Nigeria found that women in tertiary hospital for antenatal care, higher percentage in (63.5\%) women registered in 2nd trimester of pregnancy in our country due to lack of knowledge about ANC, women's attending tertiary hospitals during third trimester mostly, or when delivery is impending ${ }^{13}$.

In this study a total of 396; Among pregnant mother $64 \%$ pregnant women were anemic, indicating that anemia in pregnancy still a major problem in our country, although other study found that specially in rural area Bangladesh, the prevalence of anemia among pregnant women was $50 \%{ }^{11}$. In rural area in some NGO works for prevention of anemia by iron supplementation. In other countries in the south Asian region the Anemia prevalence in pregnant women is reportedly higher. One national estimate in India is $87 \%{ }^{14}$. From the plains of Nepal, prevalence of anemia was $73 \%{ }^{15}$. In Sri-Lanka $65 \%$ pregnant are anemic ${ }^{16}$.

In this study maximum pregnant women $(39.6 \%)$ who were interviewed are in age group between $21-25$ years. $28 \%$ were 
in age group between 26-30 years. One study found that one hundred pregnant women was attended Gynae and obs OPD of railway hospital. Mean maternal age recorded was $30.24 \pm 6.15$ years (maximum 42 years and minimum 20 years) $)^{2}$.

Among the pregnant women visited, $65 \%$ were house wife, $22 \%$ were garments worker, and $10 \%$ were service holder. As in tertiary hospitals in urban area, low economic status group patients are more visited, so, in this study service holder pregnant women were visited only $10 \%$, and $58 \%$ pregnant women's had low family income (1000-5000).

So anemia in pregnancy is common in our country, because of low socioeconomic status, women's had poor dietary status, which makes micronutrients deficiency and anemia. Education and knowledge is important to prevent anemia in pregnancy, illiteracy, ignorance detoriorus effect on mental health. Although tertiary hospital visited illiterate pregnant women were $19.7 \%, 37.63 \%$ were educated in primary level.

ANC helps to early diagnosis of anemia in pregnancy, in this study maximum $67 \%$ pregnant women had knowledge about, what is antenatal care, but $32 \%$ had no knowledge about this, ANC improve pregnant women's knowledge of its benefits. A study in Indonesia, an experimental design with 60 pregnant women from 10 cluster villages is used in this study. The intervention group received the new approach to ANC, while the control group received routine ANC. The findings show that the improvement of knowledge in the intervention group significant particularly in the knowledge about healthy pregnancy $(p=0.012)$, pregnancy complications $(p=0.01)$, safe birth $(p=0.01)$ and taking care of the newborn $(p=0.012)$. The improvement of knowledge was significantly influenced by the respondent's educational back ground $(\mathrm{p}=0.002)$ and socio-economic status $(p=0.027)$. This study in Indonesia, recommends that the new approach to ANC be considers educating pregnant women regarding safe birth and it is considered as one of the strategies that may be adopted to reduce maternal mortality ${ }^{19}$.

Ideally the pregnant mother should attend the clinic once a month during the first 7 months; twice a month during the next two months; and there after once a week. In the study $37 \%$ pregnant women had good knowledge that frequent ANC visit is necessary, but due to poor socio economic factor, poor transportation application is also poor.

Maximum 67\% pregnant women had no knowledge about anemia in pregnancy. So case of anemia is still high because most women have low consciousness about the important of anemia prevention, a similar study in community health and nutrition Research Laboratory, a bivariate analysis resulted that, knowledge, attitude, practice and the number of pregnancy were significantly associated with anemia. Using logistic linier model indicated that the lower knowledge about anemia in pregnant women will be increased risk five times more than higher and the worse practice about anemia preventive pregnant women increase anemia risk six times more than good practice ${ }^{20}$. Most of the gravid women not aware about symptoms of anemia, only $31 \%$ had knowledge about the symptoms of anemia, remaining $66 \%$ had no knowledge.

There is very high prevalence of anemia during pregnancy in Delhi, probably due to very low frequency of meat eating in India ${ }^{21}$.

In this study maximum $73 \%$ of pregnant women had poor knowledge that anemia can be corrected by changing diet, also $73.2 \%$ pregnant women do not know that, taking of iron tab during pregnancy helps to prevent anemia and only $26.8 \%$ knows daily intake iron is necessary during pregnancy. Pregnancy is probably the greatest physiological challenge to human body, iron requirements are very high in pregnancy, it is several times higher than other periods, so prevalence of iron deficiency is common in our country. Considering the daily iron requirement and bioavailability of food iron absorption, the recommended daily allowances of iron have been set $15 \mathrm{mg}$ per day. For normal women and $38 \mathrm{mg}$ for pregnant women prophylactic iron supplements, in a dose of $65 \mathrm{mg}$ of elemental iron per day from 20 weeks on words is sufficient to prevent iron deficiency anemia in mother ${ }^{21}$.

Many study showed that iron deficiency has been the most dominant factor in the causation of anemia inpregnency ${ }^{10}$.

Present study also revealed that, knowledge of anti helmithic drugs taking to prevent anemia is very poor, About $38 \%$ of the women had ascariasis and three women (1\%) had Hook worm infestation. Hook worm infestation malaria and HIV infection have been shown to be associated with severe Anemia and iron deficiency in Bangladesh. Detection of worm infestation may be improved by including stool examination for every pregnant women. Anti-helminthic therapy could be given to infested women before conception as a public health strategy to improve iron store ${ }^{16}$. In present study maximum $79 \%$ had no knowledge about the effect of Anemia on fetus Among 396 pregnant women interviewed, almost 92\% had no knowledge of benefit to treating anemia.

On the basis of $\mathrm{Hb}$ estimation, mild anemia was found maximum (67\%), moderate anemia was $(31 \%)$ and severe case of anemia was only $1 \%$. Another study in India, found that of 1150 women, $96 \%$ were anemic $(89.8 \%$ mildly anemic, $5.3 \%$ severely anemic ${ }^{21}$.

Another study of rural Bangladesh, the anemia was mild in $28 \%$, moderate $22 \%$ and none of them had severe anemia 9 . On assessing the type of anemia by peripheral blood flim, found that microcytic hypochromic anemia was highest (64\%), normocytic anemia $7 \%$ and $28.8 \%$ had normal findings microcytic hypochromic anemia resulting from iron efficiency is the most frequent from anemia $(76 \%)^{3}$. 


\section{Conclusion}

From our result, we can conclude that serum ferritin level study among pregnant women indicates that, iron deficiency anemia is a common problem in pregnancy. So, to prevent deficiency anemia during pregnancy, adequate iron supplementation should be given to pregnant women from the first trimester. Also further study is needed for better outcome.

Conflicts of Interests: None.

\section{Acknowledgment}

We would like to thank tertiary medical college \& hospital students for their help in data collection.

\section{References}

1. Allen LH. Anemia and iron deficiency: effects on pregnancy outcome. The American journal of clinical nutrition. 2000 May 1; 71(5): 1280S-4S.

https://doi.org/10.1093/ajcn/71.5.1280s

PMid:10799402

2. Sood SK, Banerji L, Ramalingaswami V. Occurrence of nutritional anaemias in tropical countries. Occurrence, causes and prevention of nutritional anaemia. Almqvist c Wiksell, Uppsala. 1968: 135-47.

3. Siteti MC, Namasaka SD, Ariya OP, Injete SD, Wanyonyi WA. Anaemia in pregnancy: Prevalence and possible risk factors in Kakamega County, Kenya. Sci J Pub Hlth. 2014; 2(3): 216-22.

https://doi.org/10.11648/j.sjph.20140203.23

4. Toteja GS, Singh P, Dhillon BS, Saxena BN, Ahmed FU, Singh RP, et al. Prevalence of anemia among pregnant women and adolescent girls in 16 districts of India. Food and Nutrition Bulletin. 2006 Dec; 27(4): 311-5.

https://doi.org/10.1177/156482650602700405

PMid:17209473

5. Mulla S, Akarte S, Mankeshwar R, Ansari S. Adverse pregnancy outcome as a result of anaemia and hyperglycaemia with special focus on time of registration and weight gain during pregnancy.

6. Breymann C. Iron supplementation during pregnancy. Fetal and maternal medicine review. 2002 Feb; 13(1): 1-29. https://doi.org/10.1017/S0965539502000116

7. Murphy JF, Newcombe RG, O'riordan J, Coles EC, Pearson JF. Relation of haemoglobin levels in first and second trimesters to outcome of pregnancy. The Lancet. 1986 May 3; 327(8488): 992-5.

https://doi.org/10.1016/S0140-6736(86)91269-9

8. Cunningham F, Leveno K, Bloom S, Spong CY, Dashe J. Williams obstetrics, 24e. Mcgraw-hill; 2014.

9. Begum M, Nessa Z. Nutritional status of school going children of a selected school of Dhaka city. Bangladesh
Journal of Scientific and Industrial Research. 2008; 43(1): 97-102.

https://doi.org/10.3329/bjsir.v43i1.850

10. Guralnik JM, Eisenstaedt RS, Ferrucci L, Klein HG, Woodman RC. Prevalence of anemia in persons 65 years and older in the United States: evidence for a high rate of unexplained anemia. Blood. 2004 Oct 15; 104(8): 2263-8. https://doi.org/10.1182/blood-2004-05-1812

PMid: 15238427

11. Hyder SZ, Persson LÅ, Chowdhury M, Lönnerdal BO, Ekström EC. Anaemia and iron deficiency during pregnancy in rural Bangladesh. Public health nutrition. 2004 Dec; 7(8): 1065-70.

https://doi.org/10.1079/PHN2004645

PMid:15548345

12. Yadi M, Ekologi Od. Wound 'dehiscen ce pasca bedah caesar.

13. Rahman ML, Nessa Z, Yesmin S, Rahman MH, Rahman CF. A Study on Prevalence of Anaemia in Pregnancy among the Women Reporting for Antenatal Care in Combined Military Hospital, Dhaka Cantonment. Journal of Dhaka Medical College. 2017; 26(2): 103-10.

https://doi.org/10.3329/jdmc.v26i2.38824

14. Kalaivani K. Prevalence \& consequences of anaemia in pregnancy. Indian J Med Res. 2009 Nov 1; 130(5): 627-33. 15. Dreyfuss ML, Stoltzfus RJ, Sherestha JB, Pradhan EK, LeClerq SC, Khatry SK. Hookworms, Malaria and Vitamin A deficiency contribute to anemia and iron deficiency among pregnant women in the plains of Nepal. Jurnal of nutrition. 2000; 1302527-36.

https://doi.org/10.1093/jn/130.10.2527

PMid: 11015485

16. Jain M. Sustainability of the effects of medicinal iron and iron rich food supplementation on haemoglobin, intelligence quotient and growth of school aged girls. Indian Journal of Community Health. 2014 Dec 31; 26(Supp 2): 279-87.

17. Agus Y, Horiuchi S. Factors influencing the use of antenatal care in rural West Sumatra, Indonesia. BMC pregnancy and childbirth. 2012 Dec;12(1): 9.

https://doi.org/10.1186/1471-2393-12-9

PMid:22353252 PMCid:PMC3298506

18. Nurdiati DS, Sumarni S, Hakimi M, Winkvist A. Impact of intestinal helminth infection on anemia and iron status during pregnancy: a community based study in Indonesia. Southeast Asian journal of tropical medicine and public health. 2001 Mar 1; 32(1): 14-22. Bhagwan SJ, SONI D, Srinivasa MN, Malhotra M. Effect of dietary 
habits on prevalence of anemia in pregnant women of Delhi. The Journal of obstetrics and gynaecology research. 2003 Apr 1; 29(2): 73-8.

https://doi.org/10.1046/j.1341-8076.2003.00079.x

PMid:12755525

19. Rusia US, Madan NI, Agarwal NE, Sikka ME, Sood SK. Effect of maternal iron deficiency anaemia on foetal outcome. Indian journal of pathology \& microbiology. 1995 Jul; 38(3): 273-9.

20. Nguyen PH, Gonzalez-Casanova I, Nguyen H, Pham H, Truong TV, Nguyen S, et al. Multicausal etiology of anemia among women of reproductive age in Vietnam. European journal of clinical nutrition. 2015 Jan; 69(1):107.

https://doi.org/10.1038/ejen.2014.181

PMid:25205323

21. Puolakka J, Jäne O, Pakarinen A, Järvinen PA, Vihko R. Serum ferritin as a measure of iron stores during and after normal pregnancy with and without iron supplements. Acta Obstetricia et Gynecologica Scandinavica. 1980 Jan; 59(S95): 43-51.

https://doi.org/10.3109/00016348009156379 